\title{
Techniques of EMG signal analysis: detection, processing, classification and applications (Correction)
}

\author{
M. B. I. Reaz, ${ }^{1 *}$ M. S. Hussain ${ }^{1}$ and F. Mohd-Yasin ${ }^{1}$ \\ ${ }^{1}$ Faculty of Engineering, Multimedia University, 63100 Cyberjaya, Selangor, Malaysia. \\ *Corresponding Author: M.B.I. Raez, Faculty of Engineering, Multimedia University, 63100 Cyberjaya, Selangor, Malaysia. Email: \\ mamun.raez@mmu.edu.my \\ Submitted: October 16, 2006; Revised: October 16, 2006; Accepted: October 16, 2006.
}

\section{ABSTRACT}

This paper was originally published in Biological Procedures Online (BPO) on March 23, 2006. It was brought to the attention of the journal and authors that reference 74 was incorrect. The original citation for reference 74, "Stanford V. Biosignals offer potential for direct interfaces and health monitoring. Pervasive Computing, IEEE 2004; 3(1):99-103." should read "Costanza E, Inverso SA, Allen R. 'Toward Subtle Intimate Interfaces for Mobile Devices Using an EMG Controller' in Proc CHI2005, April 2005, Portland, OR, USA." 